\title{
Penerapan Koreksi Warna Pada Citra Bagi Penyandang Buta Warna Parsial
}

\author{
Anggara Permana Putra ${ }^{1}$, Farrady Alif Fiolana ${ }^{2}$, Diah Arie Widhining Kusumastutie ${ }^{3}$ \\ Program Studi Teknik Elektro Fakultas Teknik Universitas Islam Kadiri \\ Jl. Sersan Suharmaji No.38 Kediri \\ E-mail: ${ }^{1}$ anggaraperpe@gmail.com, ${ }^{2}$ farradyalif@uniska-kediri.ac.id, ${ }^{3}$ diahariewk@uniska-kediri.ac.id
}

\begin{abstract}
Buta warna (Color Vision Deficiency) adalah penurunan kemampuan untuk melihat warna atau perbedaan warna. Dari total penduduk Indonesia yang berjumlah 255 juta jiwa, sebanyak $0,7 \%$ terkena kelainan genetika yang penyandangnya tidak mampu membedakan tingkat gradasi suatu warna. Sedangkan diluar Indonesia belum dapat dipastikan berkaitan jumlah penyandang buta warna, akan tetapi dalam sebuah survei sebesar $8 \%$ laki - laki di dunia adalah pengidap buta warna. Sementara persentase perempuan yang menyandang buta warna adalah $0,4 \%$. Buta warna umumnya terjadi pada sel kerucut yang terletak di retina mata manusia. Ada berbagai cara dan teknik untuk membantu penyandang buta warna mendapatkan informasi dari objek sensitif warna. Salah satunya dengan memanfaatkan pengolahan citra digital. Dalam penelitian ini penulis membahas penggunaan pengolahan citra digital untuk memanipulasi citra sehingga dapat lebih dikenali oleh penyandang buta warna menggunakan Algoritma Daltonisasi LMS, pada metode ini dilakukan simulasi ke 3 jenis persepsi penglihatan dengan memanipulasi citra pada ruang warna LMS, kemudian error pembandingan citra simulasi dengan citra asli akan dijadikan parameter penggeser untuk citra hasil. Citra hasil diujikan ke 86 responden sesuai jenis buta warna parsial yang diderita. Hasil pengujian membuktikan rata - rata tingkat pengenalan keseluruhan meningkat dari $38,61 \%$ ke $95,1 \%$ dengan besar simpangan rata-rata berubah dari $26,2 \%$ ke $5,06 \%$.
\end{abstract}

\section{Kata Kunci-Daltonisasi LMS, Buta warna parsial, CVD}

\section{Pendahuluan}

Penyampaian informasi menggunakan multimedia pada dekade akhir ini sangat signifikan dalam penggunaan warna. Sementara itu penyandang buta warna parsial atau disebut color vision deficiency (CVD) memiliki kekurangan dalam membedakan tingkat gradasi suatu warna. Dari total penduduk Indonesia yang berjumlah 255 juta jiwa, sebanyak $0,7 \%$ terkena kelainan genetika yang penyandangnya tidak mampu membedakan tingkat gradasi suatu warna.

Sedangkan diluar Indonesia belum dapat dipastikan berkaitan jumlah penyandang buta warna, akan tetapi dalam sebuah survei sebesar 8\% laki - laki di dunia adalah pengidap buta warna. Sementara persentase perempuan yang menyandang buta warna adalah $0,4 \%$.[1] Keadaan ini terjadi karena rusaknya saraf penerima warna. Baik karena masalah genetik atau cedera kimiawi, saraf yang rusak tidak dapat membedakan warna tertentu.

Ada berbagai cara dan teknik untuk membantu penyandang buta warna mendapatkan informasi dari objek sensitif warna. Salah satunya adalah kacamata analog untuk menggeser panjang gelombang tertentu yang dilakukan oleh Enchroma Vision Company atau dengan menggunakan pendekatan digital menggunakan pengolahan citra.
Penggunaan kacamata khusus ini diperlukan penyesuaian pada jenis buta warna yang dimiliki oleh seseorang secara manual, dan ketersediaan kacamata ini masih belum terjangkau ke masyarakat umum.

Sementara itu penggunaan pengolahan citra digital dapat digunakan untuk menapis sebuah citra dengan metode tertentu sehingga gradasi dari sebuah citra lebih dapat diidentifikasi. Salah satu metode yang digunakan adalah Algoritma Daltonisasi LMS. Algoritma Daltonisasi LMS adalah prosedur untuk mengadaptasi warna dalam gambar atau urutan gambar untuk meningkatkan persepsi warna pada penyandang buta warna parsial. Proses Daltonisasi LMS menggunakan informasi yang hilang pada simulasi dalam ruang warna LMS (long, medium, short) sebagai error sehingga dapat memperbaiki citra asli

Oleh karena itu dalam penelitian ini penulis mencoba menerapkan penggunaan Algoritma Daltonisasi LMS untuk memanipulasi citra sehingga dapat lebih dikenali oleh penyandang buta warna. Dengan harapan penggunaan Algoritma Daltonisasi LMS ini penyandang buta warna parsial dapat mengenali warna citra lebih baik.

\section{BAHAN DAN METODE}

\section{A. Buta Warna Parsial}

Buta warna parsial merupakan buta warna yang menyebabkan penderita tidak dapat melihat beberapa perbedaan warna yang disebabkan kerusakan maupun anomali pada sel kerucut pada retina. Pada beberapa kasus, buta warna parsial dibagi menjadi dua yaitu buta warna merah-hijau dan biru-kuning, namun kedua jenis buta warna ini sebenarnya memiliki beragam kasus yang berbeda, klasifikasi yang lebih tepat dapat dibedakan sesuai kondisi sel kerucut yang berada di retina seperti Tabel I

TABEL I. KLASIFIKASI JENIS BUTA WARNA PARSIAL BERDASARKAN KONDISI SEL KERUCUT [2]

\begin{tabular}{|c|c|c|c|c|c|c|c|c|c|c|}
\hline NO & $\begin{array}{c}\text { SISTEM SEL } \\
\text { KERUCUT }\end{array}$ & N & A & N & A & N & A & $\begin{array}{c}\text { NAMA } \\
\text { KONDISI } \\
\text { SEL } \\
\text { KERUCUT }\end{array}$ & $\begin{array}{c}\text { JENIS } \\
\text { PENGLIHATAN }\end{array}$ & $\begin{array}{c}\text { WARNA } \\
\text { PARSIAL }\end{array}$ \\
\hline 1 & $\begin{array}{c}\text { Penglihatan } \\
\text { Normal }\end{array}$ & & & & & & Trichromat & Normal & - \\
\hline 2 & Protanomaly & & & & & & $\begin{array}{c}\text { Anomalous } \\
\text { Trichromat }\end{array}$ & Buta warna parsial & $\begin{array}{c}\text { merah- } \\
\text { hijau }\end{array}$ \\
\hline 3 & Protanopia & & & & & & Dichromat & Buta warna parsial & $\begin{array}{c}\text { merah- } \\
\text { hijau }\end{array}$ \\
\hline 5 & Deuteranomaly & & & & & & $\begin{array}{c}\text { Anomalous } \\
\text { Trichromat }\end{array}$ & Buta warna parsial & $\begin{array}{c}\text { merah- } \\
\text { hijau }\end{array}$ \\
\hline
\end{tabular}

@ 2021 Anggara P.P., Farrady A.F. \& Diah Arie W.K. 


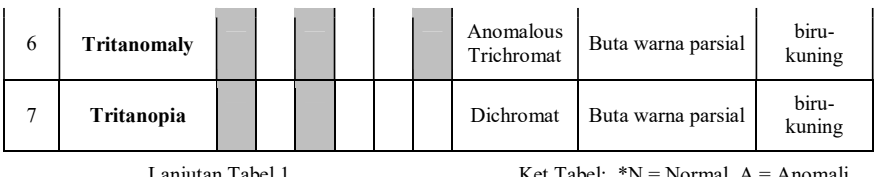

Dari tabel di atas, dapat dilihat bahwa kelaianan pada sel kerucut mata manusia secara umum dapat dibagi menjadi 2, yaitu kondisi sel kerucut mengalami anomali dan kondisi tidak adanya salah satu sel kerucut. Kemudian kedua kondisi ini dapat dibagi lagi menjadi 3 berdasarkan jenis sel kerucut.

TABEL II. PERKIRAAN PERSENTASE KEJADIAN BERBAGAI JENIS BUTA WARNA PARSIAL.[3]

\begin{tabular}{|c|c|c|}
\hline TYPE & MALE (\%) & FEMALE (\%) \\
\hline Protanopia & 1 & 0.02 \\
\hline Deuteranopia & 1.1 & 0.01 \\
\hline Tritanopia & 0.002 & 0.001 \\
\hline Protanomaly & 1 & 0.02 \\
\hline Deuteranomaly & 4.9 & 0.38 \\
\hline Tritanomaly & $\square 0$ & $\square 0$ \\
\hline Total & $\mathbf{8 . 0 0 2}$ & $\mathbf{0 . 4 4}$ \\
\hline
\end{tabular}

Sesuai dengan Tabel II bahwa kasus buta warna pada laki-laki lebih tinggi daripada perempuan. Kemudian kasus Tritanopia dan Tritanomaly merupakan kasus dengan temuan terkecil dari keseluruhan jenis kasus buta warna parsial yang diketahui.

\section{B. Ruang Warna}

Ruang warna adalah pengorganisasian beberapa warna tertentu. digunakan dalam pengkombinasian profil warna sehingga dapat mendukung berbagai perangkat fisik, dan mendukung representasi warna yang dapat direproduksi. baik representasi tersebut memerlukan representasi analog atau digital. Saat menentukan ruang warna, standar referensi yang biasa adalah ruang warna CIELAB atau CIEXYZ, yang dirancang khusus untuk mencakup semua warna yang dapat dilihat oleh manusia pada umumnya.

Dalam manipulasi citra digital ruang warna RGB (red, green, blue) merupakan standar untuk penampilan akhir citra pada sebuah layar ,Sementara itu ruang warna LMS merupakan ruang warna yang mengadaptasi cara kerja sel

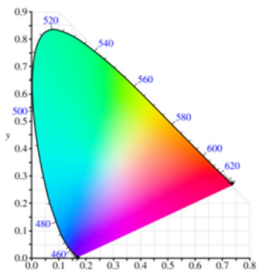

a)

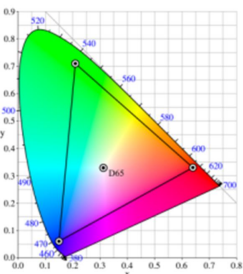

b)

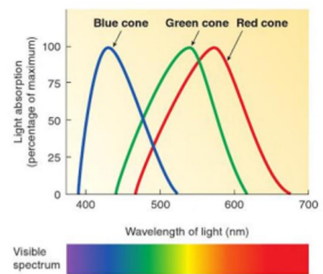

c) kerucut pada retina mata manusia.

Gambar 1. Representasi ruang warna a) CIEXYZ, b) RGB, c) LMS
Dalam sebuah pixel ketiga ruang warna memiliki 3 matrik komponen yang berbeda, X,Y,Z, Pada CIEXYZ, lalu Red, Green, Blue pada RGB dan Long, Medium, Short pada LMS. Dalam penelitian ini pembacaan dan penampilan citra akan menggunakan ruang warna RGB sementara pengolahan simulasi akan menggunakan ruang warna LMS. Konversi dari RGB ke LMS ataupun sebaliknya dapat dilakukan dengan transisi terlebih dahulu ke dalam ruang warna CIEXYZ.

\section{Algoritma Daltonisasi LMS}

Algoritma Daltonisasi LMS adalah sebuah algoritma untuk menyesuaikan warna pada gambar untuk mendapatkan warna dengan baik yang dapat dikenali oleh penampil yang kekurangan warna. Daltonisasi merupakan proses yang dilakukan pada citra yang memungkinkan orang-orang dengan kekurangan dalam pengenalan warna dapat membedakan detil warna lebih baik. dengan memanfaatkan ruang warna LMS yang mengadopsi penglihatan pada manusia. dengan mengkonversi gambar ke array dalam RGB kemudian mengkonversinya ke LMS, kemudian dilakukan simulasi tampak defisiensi warna, selanjutnya dilakukan koreksi warna berdasarkan perbedaan dari informasi warna gambar asli dengan gambar simulasi.[4]

\section{Metode Penelitian}

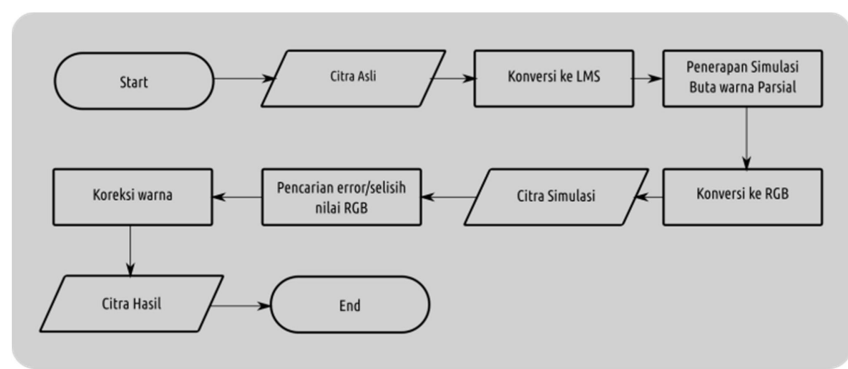

\section{Diagram Alir Sistem}

Gambar 2. Diagram Alir Sistem Koreksi Citra

Citra masukan yang berada pada ruang warna RGB dikonveri ke ruang warna LMS, kemudian setelah menghasilkan sebuah matriks setiap pixel dilakukan operasi untuk menghasilkan simulasi persepsi buta warna sesuai jenis buta warna dipilih, setelah itu dilakukan kembali konversi ulang ke ruang warna RGB, kemudian citra asli dan citra simulasi akan dibandingkan untuk mengetahui perbedaan nilai RGB setiap pixelnya, setelah mendapat nilai error selisih dari kedua citra kemudian akan dilakukan koreksi warna sesuai jenis buta warna untuk menghasilkan citra hasil.

\section{Citra Sampel}

Citra sampel yang digunakan adalah 11 citra plat tes ishihara dengan resolusi citra 768 × 789 pixel, yang didalamnya terdiri pengenalan pola angka dan jalur.

Gambar 3. Sampel plat tes ishihara yang digunakan
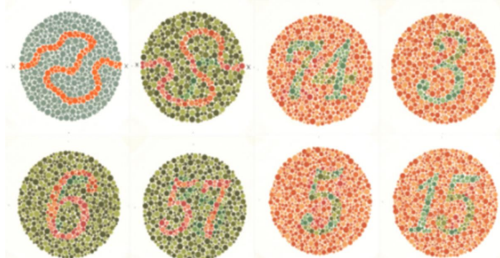

Jah Arie W.K 
Masing-masing gambar sampel memiliki pola karakter atau jalur yang dapat dikenali oleh persepsi penglihatan manusia normal, yang terdiri dari 9 pola angka, dan 2 pola jalur.

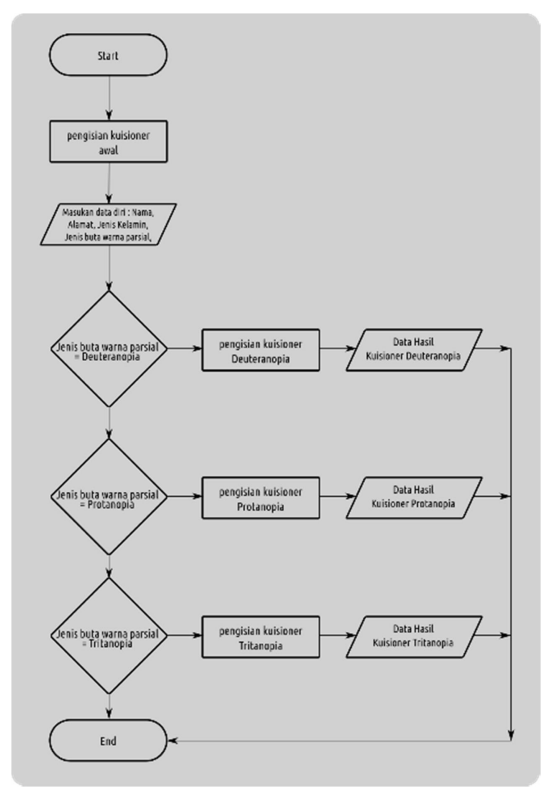

3. Metode Pengujian

Gambar 4. Diagram alir pengujian dengan kuisioner

Setiap responden mengisi satu seri kuisioner awal yang berisi 11 citra sempel yang belum diterapkan algoritma Daltonisasi LMS. Selanjutnya responden akan mengisi biodata serta memilih jenis buta warna parsial yang diderita. Kemudian kuisioner akan terbagi menjadi 3 bagian seri kuisioner yang berisi 11 citra yang telah diterapkan algoritma Daltonisasi LMS sesuai dengan jenis buta warna yang dipilih responden sebelumnya yaitu Protanopia, Deuteranopia atau Tritanopia.

Setiap seri kuisioner terdapat citra yang memiliki pola karakter maupun jalur yang terdapat didalamnya. Gambar pola yang terdapat pada kuisioner awal dan kuisioner setelah pemilihan jenis buta warna parsial memiliki urutan yang sama.

\section{HASIL DAN PEMBAHASAN}

\section{A. Simulasi Citra Buta Warna}

Pada proses simulasi ini setiap pixel citra akan diambil komponen Red, Green, Blue. Setelah itu Untuk mmengkonversi citra dengan ruang warna RGB menjadi LMS diperlukan proses konversi warna ke ruang warna CIEXYZ dengan matriks gamut yang sesuai.[5] Dapat dirumuskan sebagai berikut:

$$
M_{X Y Z}=\left[\begin{array}{lll}
0.60974 & 0.20528 & 0.14919 \\
0.31111 & 0.62567 & 0.06322 \\
0.01947 & 0.06087 & 0.74457
\end{array}\right] M_{R G B}
$$

Kemudian selanjutnya adalah konversi CIEXYZ ke LMS menggunakan Hunt-Pointer-Estevez transformation matrix (MHPE).[6] dapat dirumuskan sebagai berikut:
$M_{L M S}=\left[\begin{array}{ccc}0.4002 & 0.7076 & -0.0808 \\ -0.2263 & 1.1653 & 0.0457 \\ 0 & 0 & 0.9182\end{array}\right]\left[M_{X Y Z}\right]$

Selanjutnya dilakukan simulasi persepsi buta warna parsial pada gambar menggunakan persamaan yang menyesuaikan jenis buta warna parsial yang akan disimulasikan.[7] berikut persamaan yang akan diterapkan:

$$
\begin{gathered}
M_{L M S_{p}}=\left[\begin{array}{ccc}
0 & 2.02344 & -2.52581 \\
0 & 1 & 0 \\
0 & 0 & 1
\end{array}\right] M_{L M S} \\
M_{L M S_{d}}=\left[\begin{array}{ccc}
1 & 0 & 0 \\
0.49421 & 0 & 1.24827 \\
0 & 0 & 1
\end{array}\right] M_{L M S} \\
M_{L M S_{t}}=\left[\begin{array}{cccc}
1 & 0 & 0 \\
0 & 1 & 0 \\
-0.395913 & 0.801109 & 0
\end{array}\right] M_{L M S}
\end{gathered}
$$

kemudian dilakukan konversi kembali ke ruang warna RGB.[7] dapat dirumuskan sebagai berikut:

$$
M_{R G B_{i}}=\left[\begin{array}{ccc}
0.0809444479 & -0.130504409 & 0.116721066 \\
0.113614708 & 0.0102485335 & 0.0540193266 \\
-0.000365296938 & 0.00412161469 & 0.693511405
\end{array}\right] M_{L M S_{i}}(6)
$$

Dari matriks dihasilkan akan di konversi ulang ke ruang warna RGB setiap komponen Red, Green, Blue yang dihasilkan dari setiap pixel akan dibangun ulang menjadi

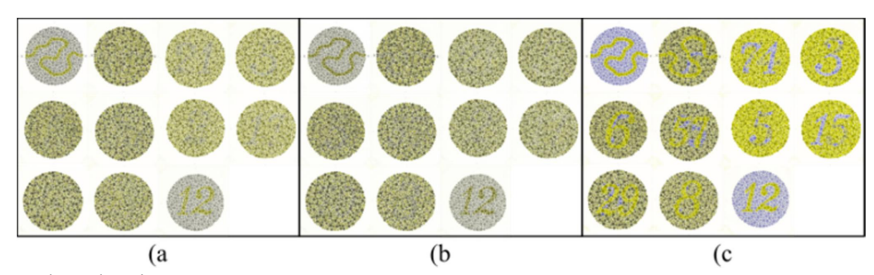

sebuah citra.

Gambar 5. Citra Simulasi a) Deuteranopia, b) Protanopia, c) Tritanopia

\section{B. Implementasi Algoritma Daltonisasi LMS}

Setelah dihasilkan citra simulasi, langkah selanjutnya adalah mencari selisih nilai komponen Red, Green, Blue pada setiap pixel pada citra asli dengan citra simulasi.[8] dapat dirumuskan seperti berikut:

$$
\begin{aligned}
& D_{r(i)}=R-R_{i} \\
& D_{g(i)}=G-G_{i} \\
& D_{b(i)}=B-B_{i}
\end{aligned}
$$

Selanjutnya adalah menggeser warna berdasar error yang telah didapatkan tadi sesuai jenis buta warna yang dipilih.[8] dapat dirumuskan seperti berikut:

$$
\begin{gathered}
{\left[\begin{array}{l}
R_{\text {map }(P)} \\
G_{\text {map }(P)} \\
B_{\text {map }(P)}
\end{array}\right]=\left[\begin{array}{ccc}
0 & 0 & 0 \\
0.7 & 1 & 0 \\
0.7 & 0 & 1
\end{array}\right]\left[\begin{array}{l}
D_{r(i)} \\
D_{g(i)} \\
D_{b(i)}
\end{array}\right]} \\
{\left[\begin{array}{l}
R_{\operatorname{map}(D)} \\
G_{\text {map }(D)} \\
B_{\text {map }(D)}
\end{array}\right]=\left[\begin{array}{ccc}
1 & 0.7 & 0 \\
0 & 0 & 0 \\
0 & 0.7 & 1
\end{array}\right]\left[\begin{array}{l}
D_{r(i)} \\
D_{g(i)} \\
D_{b(i)}
\end{array}\right]}
\end{gathered}
$$




$$
\left[\begin{array}{c}
R_{\operatorname{map}(T)} \\
G_{\operatorname{map}(T)} \\
B_{\operatorname{map}(T)}
\end{array}\right]=\left[\begin{array}{ccc}
1 & 0 & 0.7 \\
0 & 1 & 0.7 \\
0 & 0 & 0
\end{array}\right]\left[\begin{array}{c}
D_{r(i)} \\
D_{g(i)} \\
D_{b(i)}
\end{array}\right]
$$

Setelah komponen penggeser diketahui maka selanjutnya menambahkan komponen penggeser ke citra asli, dapat dilakukan dengan persamaan berikut:

$$
\begin{aligned}
& R_{F(i)}=R+R_{\text {map }(i)} \\
& G_{F(i)}=G+G_{\text {map }(i)} \\
& B_{F(i)}=B+B_{\operatorname{map}(i)}
\end{aligned}
$$

Setelah proses penggeseran komponen RGB akan dihasilkan

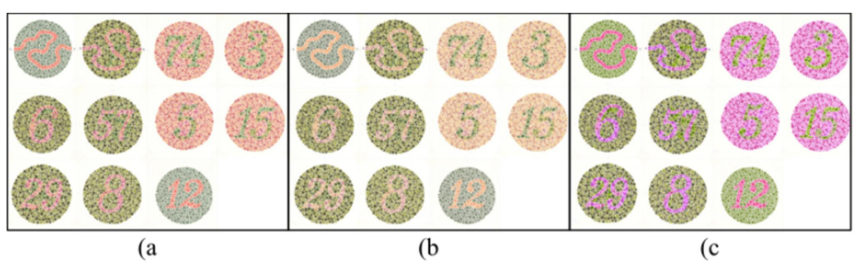

citra baru hasil Daltonisasi LMS.

Gambar 6. Citra Hasil Daltonisasi a) Deuteranopia, b) Protanopia, c) Tritanopia

\section{Pengujian Awal}

Pengujian awal dilakukan untuk mengetahui respon yang diberikan 86 responden. kemudian dapat diambil statistik tingkat identifikasi citra sebelum dilakukan Daltonisasi LMS dan persentase identifikasi pada setiap jenis buta warna parsial, serta deviasi rata - rata yang dihasilkan data pengujian awal.

TABEL III.

IDENTIFIKASI PENGUJIAN AWAL

\begin{tabular}{|c|c|c|c|c|}
\hline $\begin{array}{c}\text { Jenis buta } \\
\text { warna parsial }\end{array}$ & $\begin{array}{c}\text { Rata-rata } \\
\text { identifikasi } \\
\text { per jenis buta } \\
\text { warna parsial } \\
(\%)\end{array}$ & $\begin{array}{c}\text { Simpangan } \\
\text { rata-rata per } \\
\text { jenis buta } \\
\text { warna parsial }\end{array}$ & $\begin{array}{c}\text { Rata-rata } \\
\text { Keseluruhan } \\
(\%)\end{array}$ & $\begin{array}{c}\text { Simpangan } \\
\text { rata-rata } \\
\text { keseluruhan }\end{array}$ \\
\cline { 1 - 3 } Deuteranopia & 35.98 & 25.25 & \multirow{2}{*}{38.61} & \multirow{2}{*}{26.22} \\
\hline Protanopia & 27.57 & 28.37 & & \\
\hline Tritanopia & 52.27 & 14.26 & & \\
\hline
\end{tabular}

Dapat dilihat bahwa tingkat identifikasi dari tertinggi hingga terendah dengan tritanopia di angka 52,27\%, deuteranopia di angka 35,98\%, protanopia di angka 27,57\%. Serta rata-rata keseluruhan mencapai $38,61 \%$. Kemudian untuk simpangan rata rata dapat dilihat dari yang urutan terendah hingga tertinggi dengan tritanopia di angka 14,26, deuteranopia di angka 25,25, dan protanopia di angka 28,37, serta simpangan rata-rata keseluruhan bernilai 26,22.

\section{Pengujian Setelah Implementasi}

Pengujian ini dilakukan untuk mengetahui tingkat identifikasi dari 86 responden terhadap citra yang telah dikoreksi menggunakan algoritma daltonisasi LMS.
TABEL IV.

IDENTIFIKASI PENGUJIAN CITRA IMPLEMENTASI

\begin{tabular}{|c|c|c|c|c|}
\hline $\begin{array}{c}\text { Jenis buta } \\
\text { warna parsial }\end{array}$ & $\begin{array}{c}\text { Rata-rata } \\
\text { identifikasi } \\
\text { per jenis buta } \\
\text { warna parsial } \\
(\%)\end{array}$ & $\begin{array}{c}\text { Simpangan } \\
\text { rata-rata per } \\
\text { jenis buta } \\
\text { warna parsial }\end{array}$ & $\begin{array}{c}\text { Rata-rata } \\
\text { Keseluruhan } \\
(\%)\end{array}$ & $\begin{array}{c}\text { Simpangan } \\
\text { rata-rata } \\
\text { keseluruhan }\end{array}$ \\
\cline { 1 - 3 } Deuteranopia & 94.58 & 5.73 & \multirow{2}{*}{95.10} & \multirow{2}{*}{5.06} \\
\hline Protanopia & 94.13 & 4.05 & & \\
\hline Tritanopia & 96.59 & 4.96 & & \\
\hline
\end{tabular}

Dapat dilihat bahwa tingkat identifikasi dari tertinggi hingga terendah dengan tritanopia di angka 96,58\%, deuteranopia di angka 94,58\%, protanopia di angka 94,13\%. Serta rata-rata keseluruhan mencapai $95,10 \%$. Kemudian untuk simpangan rata rata dapat dilihat dari yang urutan terendah hingga tertinggi dengan protanopia di angka 4,05, tritanopia di angka 4,96, dan protanopia di angka 5,73, serta simpangan rata-rata keseluruhan bernilai 5,06.

\section{KESIMPULAN}

Berdasarkan data hasil kuisioner pengujian awal dan pengujian citra hasil, dapat diambil kesimpulan sebagai berikut:

1. Hasil identifikasi pada pengujian awal mendapat persentase sebesar $38,61 \%$, dengan simpangan rata - rata sebesar $26,22 \%$

2. Hasil identifikasi pada pengujian citra hasil menimbulkan peningkatan identifikasi dengan persentase sebesar 95,1\%, dengan simpangan rata - rata sebesar 5,06\%

3. Citra hasil Daltonisasi LMS meningkatkan identifikasi citra digital bagi penyandang buta warna parsial

\section{DAFTAR PUSTAKA}

[1] D. Keene, "A Review of Color Blindness for Microscopists: Guidelines and Tools for Accommodating and Coping with Color Vision Deficiency," Microsc. Microanal., vol. 21, pp. 1-11, 2015.

[2] M. J. Tovee, An Introduction to the Visual System. 2008.

[3] R. W. G. Hunt and M. R. Pointer, Measuring Colour. 2011.

[4] V. Singh and V. Thakur, "To Compensate Deuteranopia \& Protanopia: An Efficient Approach in Image Processing ( DAA )," Int. J. Trend Res. Dev., vol. 4, no. 4, pp. 197-202, 2017.

[5] Adobe Systems, "Adobe RGB (1998) Color Image Encoding," Adobe Syst. Inc., vol. 2704, no. 05/2005, pp. 1-20, 2005.

[6] N. Moroney, M. D. Fairchild, R. W. G. Hunt, C. Li, M. R. Luo, and T. Newman, "The CIECAM02 color appearance model," Final Progr. Proc. - IS T/SID Color Imaging Conf., pp. 23-27, 2002.

[7] C.-N. Anagnostopoulos, G. Tsekouras, I. Anagnostopoulos, and C. Kalloniatis, "Intelligent modification for the daltonization process of digitized paintings," Int. Conf. Comput. Vis. Syst., no. March 2017, 2007.

[8] A. Tasnim and I. I. E. X. W. Ork, "An Improved Dynamic Daltonization for Color - Blinds."
ISSN 2615-5788 Print (2615-7764) JURNAL TEKNIK ELEKTRO DAN KOMPUTER TRIAC https://journal.trunojoyo.ac.id/triac 